\title{
Covid-19: undocumented migrants are probably at greatest risk
}

\author{
Raj Bhopal emeritus professor of public health
}

Usher Institute, University of Edinburgh, Edinburgh EH3 9AG, UK

Hargreaves and colleagues have pinpointed the challenges in meeting the needs of migrants, particularly those in refugee camps. ${ }^{1}$ Undocumented migrants, however, have even greater needs. People who are undocumented do not have legal rights to residence in the country they are in; they are also in danger of becoming scapegoats as well as victims of covid-19. For obvious reasons, the numbers of such people are unknown, but immigration authorities estimate that there are hundreds of thousands in the UK.

This group is at particularly high risk for reasons including having no prior bond of trust with authorities; no bridge for communication of information through the public sector; possibly no capacity to observe the two metre and other social distancing guidance; and minimal rights to healthcare. These obstacles apply globally.

The needs of this population are a sensitive topic and opening up an objective dialogue is difficult at any time but particularly during a national emergency. In some places, xenophobia and racism are already evident. Early statistical and anecdotal evidence indicates that the pandemic is affecting all migrant and ethnic minority groups badly but statistical information about undocumented migrants is not available.

The Migrant and Ethnic Health Section of the European Public Health Association has given a statement which includes actions to protect undocumented (as well as all other) migrants. It states, "Inclusion of all migrant and ethnic minority groups in Europe into the ongoing protective measures, information campaigns, and health services provision is essential. We call for temporary suspension of any policies that may exclude migrants from accessing these measures. It is imperative that no one should feel under the threat of prosecution or deportation during this period and safeguards need to be in place."

The full statement provides the context: https://eupha.org/ repository/advocacy/MIG_statement_on_COVID19.pdf.

The organisation PICUM, which represents a platform for those working on behalf of undocumented migrants, has also released a statement setting out similar principles focused on undocumented migrants: https://picum.org/wp-content/uploads/ 2020/03/COVID-19-Statement-March-2020.pdf.

Everyone working on the covid-19 pandemic-whether in state or international policy, planning for healthcare and containment, or researching on the causes, consequences, and trajectory of the pandemic —needs to give immediate attention to this matter.

Competing interests: I am a contributor to the statement given by the Migrant and Ethnic Health Section of the European Public Health Association referred to in this letter.

Hargreaves S, Kumar BN, McKee M, Jones L, Veizis A. Europe's migrant containment policies threaten the response to covid-19. BMJ 2020;368:m1213. 10.1136/bmj.m1213 32217531

Published by the BMJ Publishing Group Limited. For permission to use (where not already granted under a licence) please go to http://group.bmj.com/group/rights-licensing/ permissions 